DOI: https://doi.org/10.24867/04BE04Gavrilov

\title{
UTICAJ SOLARNIH PANELA NA STRUJU KRATKOG SPOJA U NISKONAPONSKOJ DISTRIBUTIVNOJ MREŽI
}

\section{IMPACT OF SOLAR GENERATORS ON THE SHORT-CIRCUIT CURRENT IN LOW VOLTAGE NETWORK}

\author{
Teodora Gavrilov, Fakultet tehničkih nauka, Novi Sad
}

\section{Oblast - ELEKTROTEHNIKA I RAČUNARSTVO}

Kratak sadržaj - U radu se razmatra uticaj kućnih solarnih panela na vrednost struje kratkog spoja u niskonaponskoj distributivnoj mreži. Cilj je da se proceni pri kojoj vrednosti snage panela postoji značajan uticaj na rad zaštita u niskonaponskoj mreži. Razmatranja su ilustrovan na primeru jedne tzv. sremskom tipu naselja. Ključne reči: relejna zaštita, struja kratkog spoja, solarni paneli

Abstract - This paper deals with the impact of home solar panels on the value of the short-circuit current in the low-voltage distribution network. The aim is to evaluate where the value of the panel has a significant impact on the operation of protection in the low voltage network. The considerations are illustrated in the case of one so-called. Srem type of settlement.

Keywords: Relay Protection, Short-Circuit Current, Solar Generators

\section{UVOD}

U radu se razmatra uticaj kućnih solarnih panela na vrednost struje kratkog spoja u niskonaponskoj distributivnoj mreži. Potrošači koji imaju ove solarne panele se ponašaju kao prosumeri, odnosno kao potrošači ali i proizvođači električne energije. Cilj je da se proceni pri kojoj vrednosti snage panela postoji značajan uticaj na rad zaštita u niskonaponskoj mreži. Razmatranja su ilustrovana na primeru sremskog tipa naselja. U glavi dva definisana je niskonaponska distributivna mreža. U glavi tri dati su osnovni pojmovi o solarnim panelima. Glava četiri sadrži teorijske osnove o kratkim spojevima u elektroenergetskim sistemima (EES) sa posebnim akcentom na distributivne mreže. U glavi pet definiše se zaštita od kratkih spojeva, kao i način zaštite transformatora od njih. U glavi šest prikazan je proračun struja kratkog spoja sa ciljem pokazivanja uticaja prosumera. Zaključci rada su predstavljeni u sedmoj glavi. Na kraju je data literature u glavi osam.

\section{NISKONAPONSKA DISTRIBUTIVNA MREŽA}

Delovi elektroenergetskih sistema kojima se električna energija preuzima sa prenosnih mreža i raspodeljuje potrošačima jesu distributivne mreže. Električna energija se, u srpskom i evropskim EES, iz trofazne prenosne mreže vrlo visokog napona, Označena sa VVN, 400 i $220 \mathrm{kV}$ preuzima trofazni

\section{NAPOMENA:}

Ovaj rad proistekao je iz master rada čiji mentor je dr Duško Bekut, redovni profesor. transformatorima 400/115 i 220/115 kV/kV. Trofazni vodovi $110 \mathrm{kV}$ jesu visokonaponski vodovi, koji se napajaju sa tih transformatora. Oni čine sub-prenosnu mrežu. Električna energija se sa trofazne sub-prenosne mreže preuzima trofaznim napojnim transformatorima $110 / 21(10,5) \mathrm{kV} / \mathrm{kV}$. Subprenosna i distributivna mreža s tri naponska nivoa u Srbiji je $110 \mathrm{kV} / 20 \mathrm{kV} / 0,4 \mathrm{kV}$ (npr. u Vojvodini) ili $110 \mathrm{kV} / 10$ $\mathrm{kV} / 0,4 \mathrm{kV}$ (npr. u Beogradu). Trofazni vodovi srednjeg napona $20(10) \mathrm{kV}$ napajaju se sa trofaznih napojnih transformatora $110 / 21(10,5) \mathrm{kV} / \mathrm{kV}$. Sa ovih vodova električna energija se preuzima trofaznim distributivnim transformatorima $20(10) / 0,4 \mathrm{kV} / \mathrm{kV}$. Na osnovu toga, $\mathrm{s}$ nominalnih napona niskonaponskih strana distributivnih transformatora od $0,4 \mathrm{kV}$ prelazi se na $0,42 \mathrm{kV}$ [1]. Individualni potrošači (stanovi, itd.) napajaju se trofazno električnom energijom sa ovih niskonaponskih vodova.

\section{DISTRIBUIRANI GENERATORI}

Elektroenergetski sistemi pre uvođenja slobodnog tržišta električne energije, sastojali su se iz proizvodnog sistema, prenosnog sistema, distributivnog sistema i potrošnje i njihovo uređenje i upravljanje je bilo vertikalno. U takvom EES-u, tok energije u distributivnom sistemu tekao je samo $u$ jednom smeru, tj. od mesta preuzimanja energije (transformatorske stanice između prenosnog i distributivnog sistema) preko uglavnom radijalnih vodova i transformatorskih stanica do potrošača.

Nakon uvođenja slobodnog tržišta električne energije, osnovne komponente EES-a su ostale iste, ali je sada uređenje i upravljanje EES-om iz ,vertikalnog prešlo u ,horizontalno.

Pored uvođenja slobodnog tržišta električne energije došlo je do razvoja distribuiranih generatora [2]. Razvojem distribuiranih generatora, koji se priključuju direktno na distributivnu mrežu, dolazi do promene smera tokova snaga $\mathrm{u}$ distributivnom sistemu. Pored promene tokova snaga $u$ samoj distributivnoj mreži, dolazi do toga da distributivni sistem predaje aktivnu snagu u prenosni sistem. Distributivna mreža više nije samo pasivan deo, nego postaje ,aktivan“ deo EES-a.

Pod distribuiranim generatorima se podrazumevaju generatori manjih snaga, koji se priključuju direktno na distributivnu mrežu i koji za pogon koriste obnovljive izvore energije ili viškove energije iz nekog drugog tehnološkog (proizvodnog) procesa. Samo ime distribuirani generator nastalo iz činjenice da su izvori energije koje oni koriste rasprostranjeni po celom EES-u. Zbog navedenog, dolazi do pojave velikog broja malih elektrana koje nisu centralizovane nego su široko raspostranjene po celom EES-u, zavisno od izvora energije koji koriste. 
Distribuirani generatori se razlikuju po vrsti energenta koji koriste. Vrste distribuiranih generatora koji su trenutno najčešće u upotrebi su: mala hidroelektrana, mini hidroelektrana i mikro hidroelektrana, elektrana na vetar, solarna elektrana, termoelektrana, tj.toplana koja deo električne energije povremeno ili stalno isporučuje u mrežu, termoelektrana na biomasu, otpatke i gorivne ćelije.

\subsection{Solarni Paneli}

Solarna energija (energija Sunca) je najobilniji vid energije koji je dostupan. Sunce je neiscrpan izvor svetlosti i u budućnosti je neophodno razvijati načine korišćenja ovog oblika energije. Velika mana solarne energije je ta da ona nije konstantna tokom celog dana kao i da ima promenjivu prirodu tokom godine. Načini korišćenja solarne energije mogu da se podele $u$ dva pravca, pretvaranje solarne energije $u$ električnu energiju $i$ pretvaranje solarne energije $u$ termičku energiju [2].

Fotonaponska (FN) ćelija je osnova fotonaponskog sistema. Ona predstavlja p-n spoj koji pomoću fotonaponskog efekta sunčevo zračenje pretvara u električnu energiju. Sačinjena je od poluprovodničkog materijala (najčešće silicijuma). Usled apsorpcije sunčevog zračenja, u p-n spoju se javljaju parovi elektron-šupljina. Prilikom sunčevog zračenja unutar ili u blizini p-n spoja, unutrašnje električno polje razdvaja elektrone $\mathrm{i}$ šupljine. Pri tome se elektroni kreću prema $n$ strani, a šupljine prema $\mathrm{p}$ strani $\mathrm{p}-\mathrm{n}$ spoja, i kao posledica toga javlja se potencijalna razlika, odnosno napon. Kada se FN ćelija poveže u strujno kolo, kroz potrošač će poteći struja.

Više solarnih ćelija sjedinjenih u jednu celinu jeste solarni panel, a više panela sjedinjenih u jednu celinu predstavlja modul. U ovom radu, tokom analize uticaja solarnih panela na eventualno prepodešenje relejne zaštite, uzima se u obzir samo struja koju ovakvi paneli prosleđuju dalje u mrežu.

\section{KRATAK SPOJ}

Kratak spoj je slučajan ili nameran spoj provodnika, preko malog otpora ili impedanse, između dve ili više tačaka, koje su na različitim potencijalima, [1]. Karakteristike uređaja koji vrše prekidanje struja kratkog spoja zavise od veličine struje koju prekidaju i od vremenskog trenutka u kom se eliminiše kratak spoj. Poznavanje odvijanja prelazne pojave i veličine struje kratkog spoja koja se prekida od posebnog je značaja za podešavanje zaštitnih releja i izbor parametara prekidača i druge rasklopne opreme. Rezultati proračuna kraktih spojeva se koriste kako pri projektovanju tako i pri eksploataciji i planiranju elektroenergetskog sistema. U distributivnim mrežama, kao i u elektroenergetskim sistemima, analiziraju se sledeće vrste ktatkih spojeva: jednopolni kratki spoj, dvopolni kratki spoj bez zemlje, dvopolni kratki spoj sa zemljom i troploni kratak spoj sa i bez zemlje.

U radu se razmatra tropolni kratak spoj. Tropolni kratak spoj predstavlja simetričan slučaj kratkog spoja. Tropolni kratak spoj se zbog svojih simetričnih karakteristika najlakše interpretira i proračunava. Na mestu kratkog spoja, fazni naponi su brojno jednaki na nulu i struja kratkog spoja opterećuje fazne vodove simetrično. Neutralni vod ili zemlja ne učestvuju u provođenju struje pa je struja kratkog spoja ista, nezavisno od toga da li je zvezdište mreže uzemljeno ili izolovano. Zbog navedenog, proračun struje kratkog spoja se računa samo za jednu fazu. Verovatnoća pojavljivanja tropolnog kratkog spoja je vrlo mala, te na mestu kratkog spoja u najvećem broju slučajeva ova vrsta kratkog spoja daje najveću struju kratkog spoja.

\section{ZAŠTITA OD STRUJE KRATKOG SPOJA U NISKONAPONSKIM MREŽAMA}

Zadatak zaštite od kratkog spoja jeste da eliminiše kratke spojeve i ograniči posledice, što znači da struje nastale kratkim spojem budu prekinute u što kraćem vremenu. Uređaji koji obezbeđuju samo zaštitu od struja kratkog spoja su uređaji koji mogu biti instalisani tamo gde se zaštita od preopterećenja postiže na drugi način, ili gde nije obavezna zaštita od preopterećenja. Ovi uređaji moraju da prekidaju struju kratkog spoja sve do vrednosti očekivane struje kratkog spoja na mestu ugradnje. Takvi uređaji su: prekidači sa prekostrujnim okidačem i osigurači [3].

Osigurač je uređaj koji služi za zaštitu od kratkog spoja i preopterećenja ili samo za zaštitu od kratkog spoja. Prekidanje strujnog kola se vrši topljenjem posebno oblikovanog topljivog elementa. Ugrađuje se u razvodnim ormanima niskog napona.

\subsection{Zaštita Transformatora}

U slučaju kratkih spojeva iza transformatora, kkratak spoj predstavlja značajno naprezanje za transformator preko koga se napaja mesto kratkog spoja. Ovi kratki spojevi se isključuju zaštitom smeštenom na niskonaponskoj strani (niskonaponski osigurači ili niskonaponski prekidači), ili zaštitom na visokonaponskoj strani ispred transformatora $\mathrm{u}$ slučaju da ne reaguje zaštita na niskonaponskoj strani.

$\mathrm{Za}$ transformator $\mathrm{u}$ ovom radu, proračunate su nominalne struje primara i sekundara i spram njihovih nominalnih struja izabrani osigurači (slika 5.1).

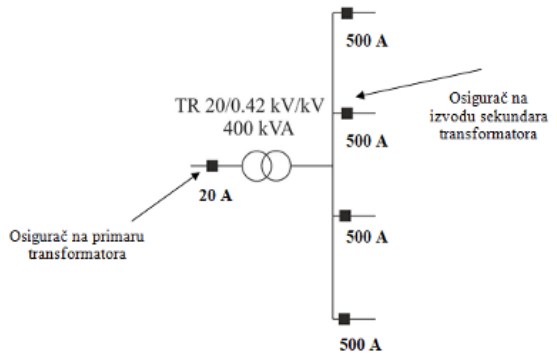

Slika 5.1 - Zaštita transformatora

\section{UTICAJ PROSUMERA NA KRATAK SPOJ I ZAŠTITU U SREMSKOM TIPU NASELJA}

U ovom delu rada su definisani prosumeri i prikazan je sremski tip naselja. Takođe su i prikazani primeri uticaja prosumera na struju kratkog spoja.

\subsection{Prosumeri}

Prosumer je reč koja je nastala iz dve engleske reči: producer (proizvođač) i consumer (potrošač). U elektroenergetskom smislu, to je potrošač energije koji je u isto vreme i proizvodi (npr. zgrade, kuće ili domaćinstva, koji na svojim krovovima imaju solarne panele), tj. oni su istovremeno proizvođači i potrošači energije, što dovodi do dvosmernog toka energije. Prosumer je i jedinica koja se može posmatrati kao početak i kraj lanca snabdevanja energijom. 


\subsection{Sremski tip naselja}

Sremski tip naselja obuhvata delove vangradskog naselja sa većom gustinom stanovanja, sa približno pravilnim rasporedom ulica i raskrsnica, spratnosti $\mathrm{P}$ i $\mathrm{P}+1$.

U ovom naselju, niskonaponska mreža je, po pravilu, nadzemna i povezuje susedne transformatorske stanice (TS), dok su transformatorske stanice slobodnostojeće ili stubne [4].

Za sremski tip stambenog naselja koriste se montažno betonska TS - MBTS (8 NN izvoda), stubne TS (4 NN izvoda) ili MTSP (4 NN izvoda).

Nadzemna niskonaponska mreža je na betonskim stubovima, povezuje susedne transformatorske stanice ili se gradi kao antenska. Granice razdvajanja mreža se izvode na stubu, na kome se obavezno povezuju neutralni provodnici. Po pravilu se koristi SKS, ali je dozvoljeno korišćenje i golih $\mathrm{Al} / \mathrm{C} e$ užadi.

\subsection{Primer uticaja prosumera}

Primer uticaja prosumera na struju kratkog spoja prikazana je na delu niskonaponske mreže. Razmatrana je jednostavna distributivna mreža sa kratkim spojem na početku i kraju izvoda. Distributivna mreža je naponskog nivoa $0.42 \mathrm{kV}$, prikazana na slici 6.1 .

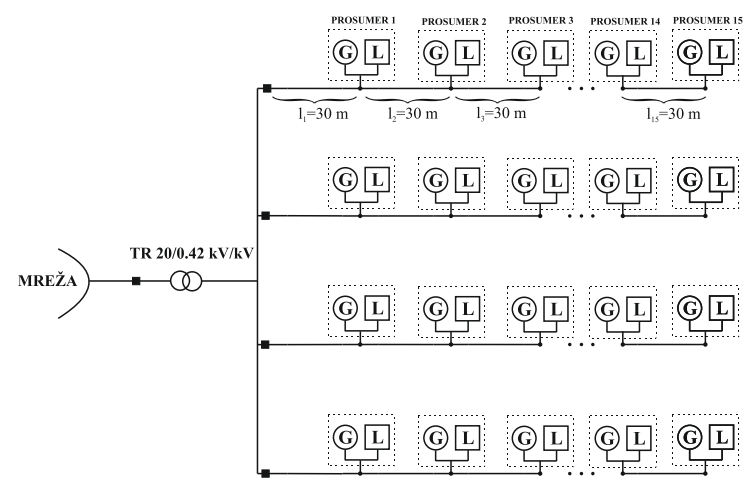

Slika 6.1 - Razmatrani deo niskonaponske mreže

Razmatran je i slučaj kada su na krajevima izvoda priključeni veliki solarni paneli, koji proizvode $50 \mathrm{~kW}$. Ovaj slučaj je prikazan na slici 6.2 .

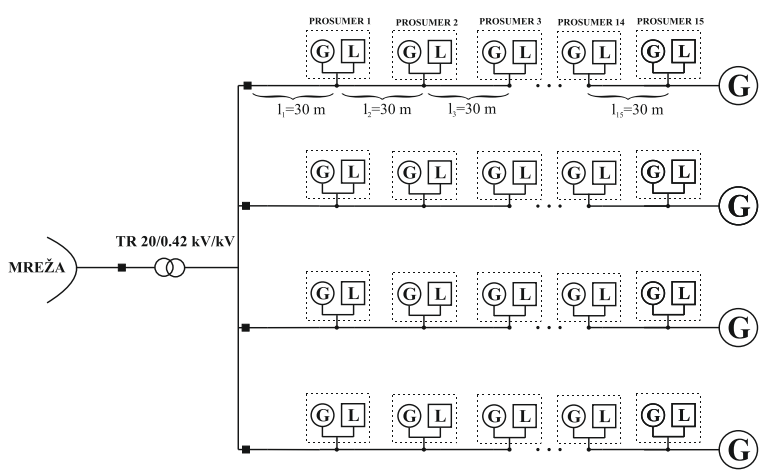

Slika 6.2 - Razmatrani deo niskonaponske mreže sa velikim solarnim panelima na krajevima izvoda

U radu su razmatrani sledeći slučajevi:

- $\quad$ prosumeri proizvode $1 \mathrm{~kW}$, i troše $5 \mathrm{~kW}$,

- $\quad$ prosumeri proizvode $2 \mathrm{~kW}, \mathrm{i}$ troše $5 \mathrm{~kW}$ i

- $\quad$ prosumeri proizvode $5 \mathrm{~kW}, \mathrm{i}$ troše $5 \mathrm{~kW}$.

Posmatran je tropolni kratak spoj na početku i na kraju izvoda za svaki od ova 3 slučaja.

\subsubsection{Kratak spoj na početku izvoda}

Prvo je posmatran slučaj kada na krajevuma izvoda nisu vezani veliki solarni paneli (slika 6.3).

Struja tropolnog kratkog spoja pri insertovanim generatorima je zbir stvarne struje tropolnog kratkog spoja pre insertovanja i struje sume svih struja koje odaju solarni generatori pri kratkom spoju.

Za struju tropolnog kratkog spoja pre insertovanja dobijeno je $15.961 \mathrm{kA}$

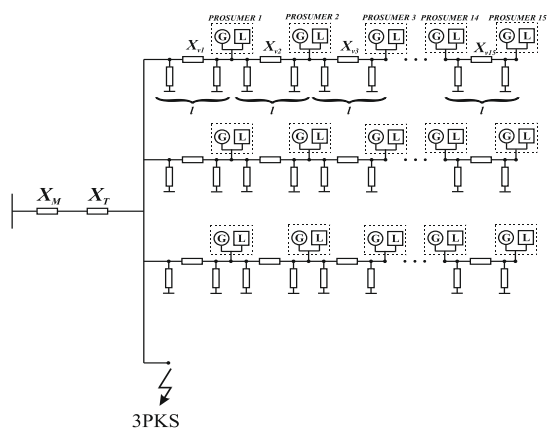

Slika 6.3 - Mreža bez velikih solarnih panela na kraju izvoda kada je kratak spoj na početku izvoda

Izračunate su sume svih struja koje odaju generatori pri kratkom spoju. $\mathrm{Na}$ svakom od 3 izvoda ima po 15 prosumera, te je ukupna struja prosumera pri kratkom spoju na početku izvoda jednaka 195.6 A (ako je proizvodnja prosumera $1 \mathrm{~kW}$ ), $391.3 \mathrm{~A}$ (ako je proizvodnja prosumera 2 $\mathrm{kW}$ ) i 978.2 A (ako je proizvodnja prosumera $5 \mathrm{~kW}$ ). Kada se te vrednosti dodaju na izračunatu struju kratkog spoja, dobija se:

- ako je proizvodnja prosumera $1 \mathrm{~kW}$ :

$\mathrm{I}_{3 \mathrm{PKS}}+\mathrm{I}_{3 \mathrm{PKS}} 1 \mathrm{~kW}=16.1 \mathrm{kA}$,

- ako je proizvodnja prosumera $2 \mathrm{~kW}$ :

$\mathrm{I}_{3 \mathrm{PKS}}+\mathrm{I}_{3 \mathrm{PKS} 2 \mathrm{~kW}}=16.3 \mathrm{kA}$,

- ako je proizvodnja prosumera $5 \mathrm{~kW}$ :

$\mathrm{I}_{3 \mathrm{PKS}}+\mathrm{I}_{3 \mathrm{PKS} 5 \mathrm{~kW}}=16.9 \mathrm{kA}$.

Drugi slučaj je kada su za krajeve izvoda priključeni veliki paneli, koju proizvode snagu $50 \mathrm{~kW}$ (slika 6.4).

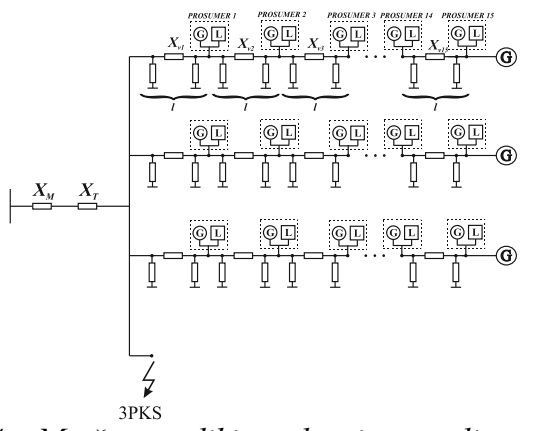

Slika 6.4 - Mreža sa velikim solarnim panelima na kraju izvoda kada je kratak spoj na početku izvoda

Struja koju veliki solarni panel proizvodi iznosi 68.7758 A. Na svakom od 3 izvoda ima po jedan veliki solarni panel, ta je ukupna struja velikih solarnih panela jednaka 206.327 A. Izračunata vrednost se sabira sa već izračunatom strujom kratkog spoja i dobija se:

- ako je proizvodnja prosumera $1 \mathrm{~kW}$ :

$\mathrm{I}_{3 \mathrm{PKS}}+\mathrm{I}_{3 \mathrm{PKS} 1 \mathrm{~kW}}+\mathrm{I}_{3 \mathrm{PKS} 50 \mathrm{~kW}}=16.3 \mathrm{kA}$,

- ako je proizvodnja prosumera $2 \mathrm{~kW}$ :

$\mathrm{I}_{3 \mathrm{PKS}}+\mathrm{I}_{3 \mathrm{PKS} 2 \mathrm{~kW}}+\mathrm{I}_{3 \mathrm{PKS} 50 \mathrm{~kW}}=16.5 \mathrm{kA}$,

- ako je proizvodnja prosumera $5 \mathrm{~kW}$ :

$\mathrm{I}_{3 \mathrm{PKS}}+\mathrm{I}_{3 \mathrm{PKS} 5 \mathrm{~kW}}+\mathrm{I}_{3 \mathrm{PKS}} 50 \mathrm{~kW}=17.1 \mathrm{kA}$. 


\subsubsection{Kratak spoj na kraju izvoda}

Posmatran je slučaj kada u mreži nema velikih solarnih panela vezanih za kraj izvoda (slika 6.5).

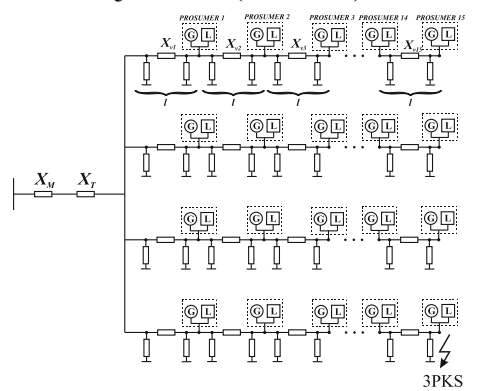

Slika 6.5 - Mreža bez velikih solarnih panela na kraju izvoda kada je kratak spoj na početku izvoda

Struja tropolnog kratkog spoja iznosi 2185.3 A.

Vrednosti struja koje proizvode prosumeri su ostale iste kao u slučaju kada je kvar na početku izvoda. Deo ukupne struje svih prosumera prolazi kroz granu u kojoj su ekvivalentna impedansa mreže kao i impedansa transformatora i deo kroz izvod na čijem kraju se računa kratak spoj (slika 6.6).

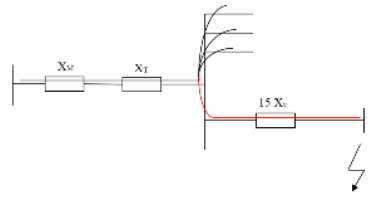

Slika 6.6 - Strujni razdelnik za ukupnu struju koju proizvode prosumeri iz izvoda na čijem kraju nije $K S$

Tražena vrednost struje kroz izvod na čijem kraju se računa kratak spoj dobija se relacijom strujnog razdelnika. Stuju prosumera priključenih na poslednji izvod se takođe računa preko strujnog razdelnika iz istog razloga (slika 6.7).

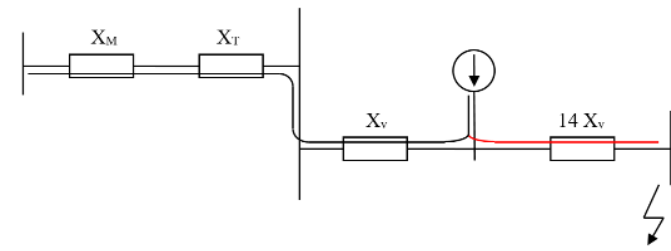

Slika 6.7 - Strujni razdelnika za struju prosumera koji su priključeni na izvod na čijem je kraju kratak spoj

Kada se dobijene vrednosti dodaju na izračunatu struju kratkog spoja, dobija se ukupna struja kratkog spoja za slučaj kada na krajevima izvoda nema velkih solarnih panela:

- ako je proizvodnja prosumera $1 \mathrm{~kW}$ :

$\mathrm{I}_{3 \mathrm{PKS}}+\mathrm{I}_{3 \mathrm{PKS}} 1 \mathrm{~kW}+\mathrm{I}_{3 \mathrm{PKS}} 1 \mathrm{~kW}$ izvod sa KS $=2257.1 \mathrm{~A}$,

- ako je proizvodnja prosumera $2 \mathrm{~kW}$ :

$\mathrm{I}_{3 \mathrm{PKS}}+\mathrm{I}_{3 \mathrm{PKS} 2 \mathrm{~kW}}+\mathrm{I}_{3 \mathrm{PKS} 2 \mathrm{~kW} \text { izvod sa KS }}=2328.9 \mathrm{~A}$,

- ako je proizvodnja prosumera $5 \mathrm{~kW}$ :

$\mathrm{I}_{3 \mathrm{PKS}}+\mathrm{I}_{3 \mathrm{PKS} 5 \mathrm{~kW}}+\mathrm{I}_{3 \mathrm{PKS} 5 \mathrm{~kW} \text { izvod sa KS}}=2544.4 \mathrm{~A}$.

$\mathrm{Na}$ kraju, posmatran je slučaj kada su za krajeve izvoda priključeni veliki paneli, koji proizvode snagu $50 \mathrm{~kW}$ (slika 6.8).

Struja koju veliki solarni panel proizvodi je ostala ista kao kada je računata struju tropolnog kratkog spoja i kada je kratak spoj bio na početku izvoda $(68,7758$ A). Kako na svakom od 3 izvoda ima po jedan veliki solarni panel, to je ukupna struja velikih solarnih panela nepromenjena (206,3A).

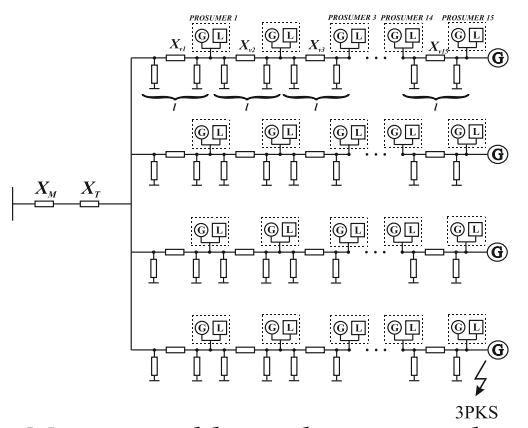

Slika 6.8 - Mreža sa velikim solarnim panelima na kraju izvoda kada je kratak spoj na kraju izvoda

Veliki solarni panel priključen na izvod na kom se računa kratak spoj ne utiče na struju kratkog spoja.

Izračunata vrednost se sabira sa već izračunatom strujom kratkog spoja kada solarni paneli nisu vezani za krajeve izvoda:

- ako je proizvodnja prosumera $1 \mathrm{~kW}$ :

$\mathrm{I}_{3 \mathrm{PKS}}+\mathrm{I}_{3 \mathrm{PKS} 1 \mathrm{~kW}}+\mathrm{I}_{3 \mathrm{PKS} 1 \mathrm{kWizvodSaKS}}+\mathrm{I}_{3 \mathrm{PKS} 50 \mathrm{~kW}}=2463.3 \mathrm{~A}$,

- ako je proizvodnja prosumera $2 \mathrm{~kW}$ :

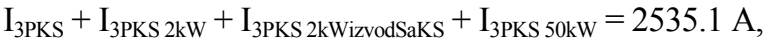

- ako je proizvodnja prosumera $5 \mathrm{~kW}$ :

$\mathrm{I}_{3 \mathrm{PKS}}+\mathrm{I}_{3 \mathrm{PKS}} 5 \mathrm{~kW}+\mathrm{I}_{3 \mathrm{PKS}} 5 \mathrm{kWizvodSaKS}+\mathrm{I}_{3 \mathrm{PKS} 50 \mathrm{~kW}}=2750.6 \mathrm{~A}$.

Kao što se može iz svih ovih primera zaključiti jeste da je uticaj prosumera na struje kratkih spojeva relativno mali i da ne postoje suštinska ograničenja za primenu solarnih panela u niskonaponskoj distributivnoj mreži.

\section{ZAKLJUČAK}

U ovom radu obrađena je tema uticaja prosumera instalisanih na individualna domaćinstva na struju kratkog spoja $u$ sremskom tipu naselja. Proračunate su vrednosti struja tropolnog kratkog spoja na početku i na kraju izvoda, sa različitim vrednostima proizvodnje prosumera, čime je pokazano da povećanjem proizvodnje prosumera raste i stuja kratkog spoja, dok vrednost potrošnje prosumera ne utiče na vrednost struje kratkog spoja. Činjenica je da što je mesto kratkog spoja bliže početku izvoda, to je struja veća. Kao što se može zaključiti iz primera u ovom radu je da je uticaj prosumera na struje kratkih spojeva relativno mali i da ne postoje ni suštinska ograničenja za primenu solarnih panela $u$ niskonaponskoj distributivnoj mreži, niti za promene $\mathrm{u}$ podešenju zaštita.

\section{LITERATURA}

[1] V. Strezoski, Analiza elektroenergetskih Sistema 1 i 2, Fakutlet tehničkih nauka Novi Sad, 2017.

[2] V. Katić, I. Kapetanović, N. Sarajlić, Obnovljivi izvori električne energije, Fakultet tehniĉkih nauka Novi Sad, 2007.

[3] EPS, Tehničke preporuke broj 14, EPS 2001.

[4] Strahil Gušavac, Osnovni principi projektovanja u mrežama srednjeg i niskog napona, Fakultet Tehničkih Nauka Novi Sad, 2004.

\section{Kratka biografija:}

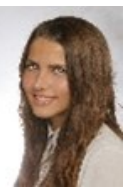

Teodora Gavrilov rođena je u Novom Sadu 1994. godine. Master rad je odbranila 2019. godine na Fakultetu tehničkih nauka iz Elektrotehnike i računarstva - Elektroenergetski sistemi. 